\title{
Assimilação de conceitos na Matemática: uma possibilidade metodológica aplicada ao ensino a distância
}

\author{
Concepts assimilation in Mathematics: a methodological possibility to \\ distance learning
}

\author{
Severina Andréa Dantas de Farias ${ }^{1}$ \\ Rogéria Gaudencio do Rêgo ${ }^{2}$
}

\begin{abstract}
RESUMO
Este trabalho propõe uma discussão metodológica de ensino aplicada ao curso de Licenciatura em Matemática a distância da Universidade Federal da Paraíba, a partir da Teoria da Aproximação da Atividade e da Resolução de Problemas, com foco no estudo de triângulos, em Geometria. A pesquisa foi de caráter exploratório, do tipo quantitativo e qualitativo, na qual foram utilizados vários instrumentos para produção e aquisição de dados. Participaram de todas as etapas do estudo, que teve duração de oito meses consecutivos, 31 estudantes do $5^{\circ}$ período do Curso investigado. Os resultados indicaram que as metodologias utilizadas foram relevantes para o desenvolvimento das tarefas matemáticas propostas aos participantes. Concluímos que as teorias discutidas contribuíram efetivamente para a assimilação conceitual trabalhada junto aos sujeitos da pesquisa.
\end{abstract}

Palavras-chave: Ensino-aprendizagem. Metodologia de Ensino. Ensino de Matemática.

\begin{abstract}
This work proposes a methodological discussion of teaching applied to the distance course in Mathematics at the Federal University of Paraíba, based on the Theory of Activity Approximation and Problem Solving, focusing on the study of triangles, in Geometry. The research was exploratory, quantitative and qualitative, in which several instruments were used for the production and acquisition of data. 31 students from the 5th period of the investigated course participated in all stages of the study, which lasted eight consecutive months. The results indicated that the methodologies used were relevant to the development of the mathematical tasks proposed to the participants. We conclude that the theories discussed contributed to the conceptual assimilation worked with the research subjects.
\end{abstract}

Keywords: Teaching and Learning. Teaching Methodology. Math teaching.

\footnotetext{
${ }^{1}$ Professora do Centro de Educação da Universidade Federal da Paraíba - CE/UFPB. ORCID: https://orcid.org/0000-0002-4526-5235. E-mail: andreamatuab@gmail.com.

2 Professora do Centro de Ciências Exatas e da Natureza da Universidade Federal da Paraíba -

CCEN/UFPB ORCID: https://orcid.org/0000-0003-4618-7213. E-mail: rogeriaedumat@gmail.com.
} 


\section{Introdução}

O Brasil conta hoje com avanços expressivos quanto ao acesso dos estudantes à escola, em especial no Ensino Fundamental. Passada a etapa de garantir o acesso dos estudantes aos ambientes escolares, surgem outras demandas sociais que impulsionam os estudos voltados à melhoria da educação em nosso país, visando à superação de problemas diversos nas instituições escolares, tais como: a violência no ambiente escolar; a falta de motivação de alunos e professores, dentre outros igualmente importantes. Neste contexto, também nos questionamos sobre a omissão da escola em seu papel de educar e formar o estudante para o exercício pleno da cidadania.

Se, de modo geral, a Educação Básica brasileira apresentou avanços nas últimas décadas quanto à cobertura de atendimento, ainda enfrenta problemas de naturezas diversas, relacionadas à qualidade do ensino. No caso específico da Matemática, os baixos níveis de desempenho têm marcado os resultados de avaliações nacionais e internacionais das quais têm participado nossos estudantes (BRASIL, 2019).

O espectro a partir do qual podemos analisar os problemas do ensino de Matemática, particularmente, é amplo, e jamais poderíamos abarcar com profundidade algum nuance se propuséssemos uma larga gama temática de discussão. Desse modo, o presente estudo visa discutir possibilidades metodológicas de ensino desenvolvidas e aplicadas a estudantes do $5^{0}$ período do Curso de Licenciatura em Matemática da Universidade Federal da Paraíba UFPB, no período de oito meses de investigação de campo.

Diante da complexidade de tais questões e de tantas necessidades preteridas, tentamos responder neste estudo a seguinte problemática de pesquisa: Quais tarefas baseadas na Teoria da Aproximação da Atividade e na Resolução de Problemas, envolvendo o conceito de triângulos, podemos propor a estudantes do curso de Licenciatura em Matemática na modalidade a distância, de forma a favorecer a sua aprendizagem? 
Assim, elegemos como objetivo geral desse estudo identificar as contribuições de uma metodologia de ensino baseada na Teoria da Aproximação da Atividade e na Resolução de Problemas, dirigida a estudantes da Licenciatura em Matemática, na modalidade a distância. Visando alcançar o objetivo de estudo elegemos como objetivos específicos: identificar o perfil dos alunos e da instituição de ensino investigada; diagnosticar o nível de desenvolvimento cognitivo dos estudantes no início do estudo; estruturar um sistema didático baseado na Teoria da Aproximação da Atividade e na Resolução de Problemas; e, por fim, avaliar a proposta, respeitando as especificidades dos discentes e da modalidade de ensino considerada.

Diante da necessidade de formação de professores para a rede de ensino do Estado da Paraíba e dos altos índices de evasão de turmas iniciantes do curso de Licenciatura em Matemática, realizamos a presente pesquisa, na expectativa de colaborarmos com a melhoria de sua formação (Farias, Rêgo, 2016). A abordagem empírica, aliada aos aspectos teóricos constituíram base de argumentação da defesa da sistematização planejada de tarefas, baseada na Teoria da Aproximação da Atividade - TAA, proposta por Talizina (2000), para potencializar a construção de conceitos relativos a triângulos, em graduandos da Licenciatura em Matemática na modalidade a distância-

\section{O Ensino e a Aprendizagem de Matemática}

O processo de ensinar se baseia na atividade do professor no exercício da profissão (ensino) e na aprendizagem do aluno. Desta forma, quando o processo é exitoso, o professor ensina (algo) e o aluno aprende (algo). A relação entre professor e aluno é secular e na atualidade reconhecemos a necessidade de colaboração entre ambos.

O êxito dos estudantes requer a colaboração não só do professor, mas também de seus pares. Contudo, o papel do professor ainda é de fundamental importância na apresentação do conhecimento social ao estudante, através de 
modelos que lhe possibilitem uma boa orientação. Com a ajuda do professor, os alunos poderão compreender a essência dos conceitos que constroem.

A aprendizagem depende também da efetiva relação entre os sujeitos e o objeto de conhecimento. Baseado nesse princípio, concebemos que o sucesso de qualquer proposta de ensino está, portanto, diretamente ligado a três fatores básicos: o objetivo do ensino (Para que ensinamos?); os conteúdos de ensino (O que ensinamos?); e o processo de aprendizagem (Quais métodos adotamos para ensinar?).

Na Educação a Distância - EaD, normalmente o estudante encontra-se em lugar geograficamente distinto em relação ao professor. Para obtermos êxito no processo educativo desse público necessitamos elaborar propostas didáticas que antecipem suas dificuldades. Com esse intuito, para produzirmos materiais didáticos para cursos a distância, Aretio $(2004$; 2006) indica algumas categorias de qualidade que devem ser atentadas, no intuito de amenizar ou extinguir futuras dificuldades provenientes do conteúdo ministrado a distância.

Tais características são organizadas em dezesseis classes: programação; adequação; precisão e atualidade; integralidade; integração; abertura e flexibilidade; coerência; eficácia; transferência e praticidade; interatividade; significativos; validade e confiabilidade; representatividade; auto avaliação; eficiência e padronização. Para um maior aprofundamento desta discussão aconselhamos a leitura de Farias (2009).

Também percebemos que a maioria dos programas curriculares das instituições de ensino não indica, de forma específica, atividades que potencializem os meios lógicos de pensamento disciplinar. Como resultado, o pensamento lógicomatemático do estudante não é, em geral, desenvolvido e quando isso ocorre é feito de forma espontânea, sem o conhecimento do sistema dos meios necessários, de seu conteúdo e da sequência de sua formação. Esta conduta leva a muitas dificuldades posteriores, em níveis mais complexos de ensino.

Assim, o estudante se apoia em características irrelevantes e isoladas do objeto a ser aprendido; memorizara definições, mas não aprende a trabalhar com esse objeto em contextos diferentes. Para superar essa lacuna ele precisa conhecer as 
características necessárias e suficientes do conceito, sendo o professor responsável por mediar à diferenciação destas características, ajudando-o no seu desenvolvimento.

\subsection{A Teoria da Aproximação da Atividade aplicada ao Ensino}

A Teoria da Aproximação da Atividade proposta por Talizina (2000) e Talizina, Solovieva e Rojas (2010) foi baseada nos estudos de Vygotsky (2007), de Leontiev (1991) e de Galperin (2009), dentre outros pesquisadores. Dando continuidade à perspectiva histórico-cultural, a autora propõe sete etapas da ação que possibilita ao estudante adquirir uma assimilação completa de qualquer conteúdo didático, acreditando que toda ação humana é motivada por uma atividade. Tais etapas são categorizadas em: etapa material ou materializada; etapa perceptiva concreta; etapa perceptiva abstrata; etapa verbal externa; etapa verbal interna; etapa imagem interna; e, por fim, a etapa mental.

Talizina (2000) afirma que o conhecimento dos planos (externo e interno) e das formas das ações (material ou materializada; perceptiva concreta ou perceptiva abstrata; verbal externa, verbal interna, imagem interna e mental) é essencial para o desenvolvimento de propostas metodológicas eficientes de ensino e para realização de correções de problemas de aprendizagem escolar. No nosso trabalho elegemos cinco categorias de investigação: a criação (presente em Galperin (2009)); a etapa material ou materializada; a etapa verbal externa; a etapa verbal interna; e, por fim, a etapa mental (presentes em Talizina (2000)).

$\mathrm{Na}$ primeira etapa, de criação, o professor deve realizar a elaboração de um projeto de ação, composto por uma base orientadora que servirá de referência para a realização da ação pelo estudante. Após a etapa de criação, seguimos para a etapa material (ou materializada), onde a ação passa pela primeira forma de construção externa pelo aluno. Na terceira etapa, verbal externa, a ação se separa das coisas (ou de suas imagens materiais) e passa para o plano da linguagem, em voz alta (verbal externa).

Em seguida, a ação é realizada mediante a conversão para si, mas ainda imprecisa em seus componentes verbais e conceituais. Trata-se da etapa verbal interna. Seguindo, a ação passa do plano externo para o plano interno na linguagem 
para si, sendo assimilada por completo na etapa seguinte, a mental. Nesta última etapa, a ação transforma-se em um processo automático e, como consequência, chega à consciência do indivíduo, sendo assimilada (GALPERIN, 2009).

Desse modo, a linguagem participa de todas as etapas de formação da ação mental, mas de diferentes modos. As ações que estão incluídas na atividade escolar com relação aos aspectos motivacionais e aos objetivos conduzem a sistemas diferentes. No ensino tradicional, o conhecimento se encontra no centro da atenção. O professor expõe o conteúdo da matéria existente nos programas de ensino, procedendo da seguinte forma: "passa" algo (conteúdo) para os estudantes, que não é explicitado com profundidade (essência).

Para solucionar esse problema o professor necessita de uma Base Orientadora da Ação - BOA, que é entendida como o sistema de condições ao qual o sujeito deve se apoiar durante a realização da ação. Ao passar de uma etapa a outra do processo, a ação se modifica e é assimilada pelo estudante, transformando-se em um novo conhecimento, cujas características são essenciais e relevantes, necessárias e suficientes para o estabelecimento da aprendizagem, sendo acompanhada pelas etapas de controle. Mas como realizarmos tais etapas no ensino a distância? Esta discussão será apresentada a seguir.

\subsection{A Resolução de Problema e o Ensino da Matemática Escolarizada}

A Resolução de Problemas é uma metodologia de ensino de Matemática proposta por diversos autores como: Polya (2006); Pozo (1998); Dante (2000); Van de Walle (2009); dentre outros, que defendem que os estudantes devem desenvolver a capacidade de resolver problemas não apenas para aplicá-los à Matemática, mas para apreender novas ideias e elaborar novos conhecimentos.

Um problema é entendido aqui como uma situação que um indivíduo ou um grupo quer ou precisa resolver e para o qual não dispõe de um caminho rápido e direto que leve à solução. Essa nova situação se diferencia de um exercício à medida que neste último utilizamos mecanismos que nos levam, de forma imediata, à solução. A realização de exercícios se baseia no uso de técnicas rotineiras que permitem consolidar esta prática ao resolver situações também rotineiras (POZO, 1998). 
A Resolução de Problemas baseia-se na apresentação de situações abertas e sugestivas que exigem dos alunos uma atitude ativa e um esforço para buscar suas próprias respostas, construir seu conhecimento. $\mathrm{O}$ ensino baseado na solução de problemas pressupõe promover nos alunos o domínio de procedimentos, assim como a utilização dos conhecimentos disponíveis, para dar respostas a situações variáveis e diferentes.

A solução de problemas estaria, portanto, mais relacionada à aquisição de procedimentos (conjunto de ações organizadas para a execução de uma meta). Deste modo, ensinar a resolver problemas não consiste somente em dotar os alunos de habilidades e estratégias eficazes, mas também em criar neles o hábito e a atitude de enfrentar a aprendizagem como um problema para o qual deve ser encontrada uma resposta (POZO, 1998).

Assim, ensinar o aluno a resolver problemas pressupõe dotá-lo da capacidade de aprender a aprender, no sentido de habilitá-lo a encontrar, por si mesmo, respostas às perguntas que o inquietam ou que precisa responder, ao invés de esperar uma resposta já elaborada por outros e apresentada no livrotexto ou pelo professor (Pozo, 1998). O verdadeiro objetivo final da aprendizagem de solução de problemas é fazer com que o aluno adquira o hábito de elaborar problemas e de resolvê-los como forma de aprender.

Com base nessa assertiva nos perguntamos: Como as pessoas resolvem problemas? Pozo (1998) afirma que existem duas formas diferentes de resolver problemas: por um processo geral aplicável da mesma forma a todas as áreas (habilidade geral); e por um conjunto de processos específicos a cada uma das áreas de conhecimento (habilidade específica).

No primeiro caso, a solução de problemas como habilidade geral está baseada em Polya (2006), que afirmou que para solucionar um problema é necessário colocar em ação uma ampla série de habilidades e conhecimentos. Este autor defende que existem dois tipos de problema: o dedutivo (demonstração) e o indutivo (estabelecimento de regularidades). Existe ainda uma dicotomia clara entre problemas bem definidos, onde é possível identificar facilmente o que se quer e se foi alcançada uma solução, presentes, geralmente, nas ciências 
naturais, e problemas mal definidos, que são pouco estruturados e admitem várias soluções, geralmente presentes nas ciências sociais.

Segundo Polya (2006), para resolvermos problemas matemáticos devemos desenvolver quatro passos: 1) compreender o problema (identificar as perguntas explícitas e implícitas); 2) conceber um plano (levantar estratégias possíveis); 3) executar o plano (materializar o uso das estratégias); e 4) fazer uma visão retrospectiva (testar a resposta e analisar sua pertinência).

Já para a solução de problemas como um processo específico, os estudos de Pozo (1998) indicaram a existência de diferenças entre especialistas e principiantes. Os principiantes resolvem os problemas de acordo com as etapas sugeridas por Polya (2006). Já os especialistas tentam inicialmente conhecer, por meio da experiência e dos conhecimentos específicos numa determinada área ou domínio de conhecimentos, como estes conhecimentos afetam a solução de um problema próprio da sua área. Solucionar problemas, nesta perspectiva, não depende da disposição de estratégias ou habilidades gerais e transferíveis, válidas para qualquer caso, mas sim dos conhecimentos específicos úteis do executor.

Pozo (1998) elege pressupostos básicos que os especialistas possuem para solucionar problemas. São estes: as habilidades e estratégias de solução de problemas são específicos; maior eficiência; maior rapidez; efeito da prática; depende da disponibilidade e conceitos adequados e diferentes maneiras de enfrentar o problema. Assim, os especialistas são mais rápidos ao resolverem problemas específicos de sua área; cometem menos erros; usam estratégias diferentes; reconhecem com mais facilidades os problemas; executam o plano de ação com rapidez e eficiência; costumam percorrer os passos 2 e 3 da heurística de Polya (conceber e executar um plano), dentre outros.

Pozo (1998) sugere que alguns procedimentos devem ser seguidos na resolução de problemas específicos de uma área, segundo seus conteúdos, que podem ser divididos em conteúdos conceituais e conteúdos procedimentais. Estes últimos podem ser subdivididos em cinco etapas: aquisição da informação (observação); interpretação da informação (decodificação); análise da informação e realização de inferências 
(comparação com Polya: passos 2 e 3); compreensão e organização conceitual da informação; e por último, comunicação da informação (oral, escrita, outros).

O que transforma a solução de um problema em um conteúdo procedimental é que este consiste em saber fazer algo e não só dizê-lo ou compreendê-lo, ao passo que existem duas formas de conhecer o mundo: através do conhecimento declarativo (saber o quê; é fácil verbalizar) e do conhecimento procedimental (saber como; é difícil verbalizar). O procedimento automatiza o conhecimento. A natureza dos procedimentos pode ser de modo intencional e deliberado (Pozo, 1998).

Considerando as discussões aqui apresentadas e o alto índice de evasão nas turmas iniciantes do curso de Licenciatura em Matemática a distância da UFPB (Farias, 2009), este estudo sistematizou tarefas baseadas na Resolução de Problemas e na Teoria da Aproximação da Atividade, aliadas ao uso de aplicativo matemático, visando potencializar a construção de conceitos matemáticos e melhorar a qualidade do ensino ofertado aos participantes do estudo.

\section{Procedimentos Metodológicos}

Em nossa investigação, de natureza quali-quantitativa, adotamos uma perspectiva metodológica predominantemente exploratória, que foi definida por Gil como tendo "[...] a principal finalidade de esclarecer e modificar conceitos e ideias, tendo em vista a formulação de problemas mais precisos ou hipóteses pesquisáveis para estudos posteriores" (GIL, 2011, p. 27).

Quanto ao levantamento e análise de dados, elegemos este estudo como sendo de caráter empírico e nos respaldamos na produção e coleta de dados através de um questionário semiestruturado e de observações diretas dos estudantes ao realizarem as tarefas, com registros efetuados por nós em um diário de campo.

A metodologia de ação correspondeu à elaboração e aplicação de tarefas diversificadas, coerentes com cada etapa da assimilação da ação e de acordo com o grau de complexidade exigido pelas etapas. Os estudantes, inicialmente, foram convidados a construírem empiricamente essas tarefas, usando a ferramenta agrupamento no ambiente de aprendizagem Moodle e o software Geogebra. 
Durante catorze semanas distribuídas em oito meses consecutivos de aplicação em campo, elaboramos, discutimos e executamos a pesquisa. No último momento da investigação constatamos que trinta e quatro (34) estudantes estariam aptos a participar da verificação final, de forma voluntária, por terem participado integralmente das etapas anteriores do estudo.

\section{Apresentação e Discussão dos Resultados}

Após realizarmos um estudo aprofundado de nosso referencial teórico, planejamos os passos seguintes da pesquisa e a fase de atividade de campo, executando e avaliando os estudantes de forma direta e contínua, o que nos possibilitou alcançar os objetivos traçados no início de nossa investigação.

A primeira etapa do estudo foi a etapa de criação, que foi subdividida em dois aspectos: diagnóstico e cognitivo. Utilizamos o ambiente Moodle, de forma não presencial, em 14 polos participantes distribuídos em municípios da Paraíba, a partir de um questionário semiestruturado composto por duas partes: levantamento de perfil e situação-problema.

Participaram da etapa do levantamento do perfil 67 estudantes (69\%) de 97 matriculados no $5^{\circ}$ período do Curso de Licenciatura em Matemática, sendo identificados os percentuais relativos aos principais itens coletados na Tabela 1:

Tabela 1 - Perfil dos estudantes

\begin{tabular}{l|l}
\hline \multicolumn{1}{c|}{ Itens } & \multicolumn{1}{c}{ Respostas } \\
\hline Gênero & $62,6 \%$ masculino \\
\hline Faixa etária & $47,8 \%$ com idade entre 20 a 30 anos \\
\hline Estado civil & $61,2 \%$ casados \\
\hline Renda familiar & $31,3 \%$ ganham de 1 a 2 salários mínimos \\
\hline Localização & $85,5 \%$ residem na zona urbana \\
\hline Qual sua Profissão & $65 \%$ estão desempregados ou nunca trabalharam \\
\hline Você já é professor & $34,8 \%$ já atuam como professores em sua região \\
\hline $\begin{array}{l}\text { Escolha do curso de Licenciatura } \\
\text { em Matemática a distância }\end{array}$ & $\begin{array}{l}(73,5 \%) \text { - identificação com a disciplina; 56,3\%) } \\
\text { flexibilidade de horário; } 23,4 \% \text { cursar uma graduação. }\end{array}$ \\
\hline
\end{tabular}

Fonte: Construção das autoras baseados em 67 questionários 
Com relação ao aspecto cognitivo, apresentamos no Quadro 1 o enunciado da questão proposta na etapa diagnóstica, com o intuito de verificar os conhecimentos dos discentes sobre o conceito de triângulo no momento inicial do estudo.

\section{Quadro 1 - Enunciado da questão diagnóstica}

1 - Certo professor de Matemática ao preparar uma aula para uma turma de $9^{\circ}$ ano do Ensino Fundamental colocou a seguinte questão para que os estudantes resolvessem:

Dispomos de três pedaços de madeira com tamanhos de $2 \mathrm{~cm}, 4 \mathrm{~cm}$ e $10 \mathrm{~cm}$. Pergunta-se:

a) Qual representação geométrica plana que podemos formar com estes três pedaços de madeira?

b) É possível obtermos um desenho desta representação? Caso afirmativo, esboce o desenho ou descreva sua resposta em texto.

c) É possível calcularmos a área e o perímetro da figura representada?

d) Caso o item anterior seja afirmativo, descreva todo o procedimento para obtermos tais resultados. (A resposta pode ser em forma de texto ou utilizando a simbologia matemática).

2- A questão 01 está adequada aos estudantes de $9^{\circ}$ ano do Ensino Fundamental? Por quê?

3- Quais seriam as possíveis dificuldades que os estudantes do $9^{\circ}$ ano do Ensino

Fundamental encontrariam ao se depararem com a questão 01? Explique.

\section{Fonte: Construção das autoras}

Para responder as questões apresentadas no Quadro 1, oferecemos a possibilidade de manipulação do Objeto de Aprendizagem (OA) que consta na Figura 1, com a simulação da construção de triângulos quaisquer, podendo ser classificados em possíveis (ou não) a partir da situação anterior, utilizando o aplicativo Geogebra.

Figura 1 - Objeto de Aprendizagem na construção de triângulos possíveis

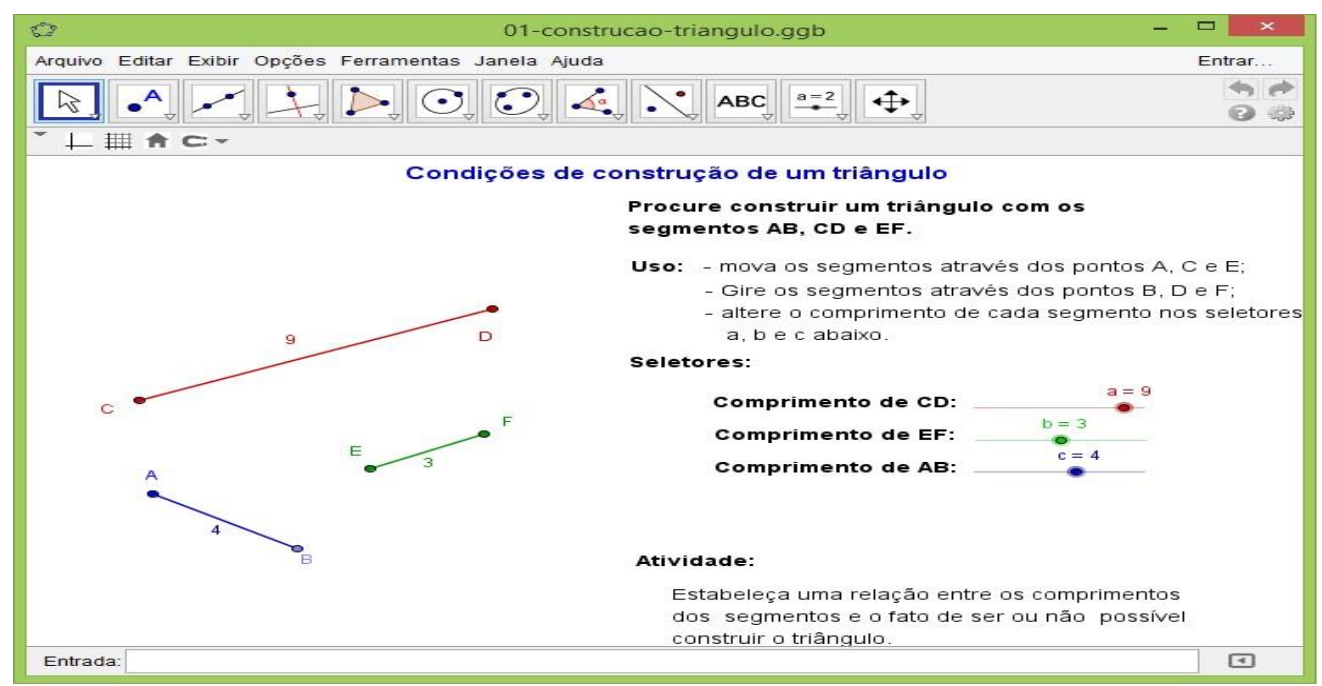

Fonte: Construção das autoras 
A esse respeito faz-se necessária uma reflexão, pois a questão propunha aos participantes a construção de triângulos possíveis. Para isso, era necessário compreender o conceito de triângulo e suas características relevantes e necessárias.

A maioria dos estudantes não conseguiu responder os itens e perceber que não poderíamos formar triângulos com as informações apresentadas no Quadro 1 (61,2\%). Além de não perceberem isso, os estudantes fizeram afirmações de que a figura se tratava de um triângulo do tipo escaleno; sua representação na forma de um desenho; o cálculo de sua área utilizando a fórmula simplificada de área de triângulo, mesmo sem as informações necessárias para isso, no caso, as medidas de sua base e altura.

O estudo de triângulos é indicado em todas as etapas da Educação Básica, de forma obrigatória (BRASIL, 1998; 2017), mas, apesar da "visibilidade" do conteúdo verificamos que a maior parte dos estudantes investigados não foi capaz de resolver a situação de reconhecimento de um triângulo, que deveria estar presente no repertório de todo estudante ao fim de sua escolaridade básica. Este é um fato preocupante, já que os participantes do estudo são futuros professores de Matemática.

A partir da primeira etapa (aplicação e análise dos resultados do Questionário), iniciamos a elaboração das tarefas, de acordo com o pressuposto teórico adotado, seguindo a orientação da Base de Orientação da Ação (BOA), partindo de conceitos simples à complexos, de forma detalhada à sintetizada, sendo construído um cartão com as principais orientações para os estudantes, (Quadro 2). 


\title{
Quadro 2 - BOA para o estudo de triângulos no Ensino Básico
}

\author{
Base Orientadora da Ação - Estudo de Triângulos \\ Observar se existe uma figura fechada. \\ Identificar se existem três lados na figura. \\ Identificar se a figura possui três ângulos internos. \\ Identificar os valores dos lados e dos ângulos. \\ Verificar se a soma dos ângulos internos do triângulo totaliza $180^{\circ}$. \\ Verificar se a soma de dois lados da figura é maior ou igual ao terceiro lado (Desigualdade \\ triangular). \\ Realizar esta verificação com todos os pares de lados. \\ Identificar características típicas, como área e perímetro da figura; \\ Os valores formam uma figura de três lados fechados? Então é possível calcular sua área e \\ perímetro, independentemente de quaisquer medidas de seus ângulos internos, utilizando a \\ fórmula de Heron $\mathrm{A}^{2}=[\mathrm{p} .(\mathrm{p}-\mathrm{a}) .(\mathrm{p}-\mathrm{b}) .(\mathrm{p}-\mathrm{c})]$. Onde \\ $\mathrm{p}=(\mathrm{a}+\mathrm{b}+\mathrm{c}) / 2$.
}

Existem apenas informações sobre dois lados, mas o triângulo é composto por um ângulo interno reto? Logo, é possível utilizar o Teorema de Pitágoras: o quadrado da hipotenusa é igual à soma dos quadrados de seus lados $\left(\mathrm{a}^{2}=\mathrm{b}^{2}+\mathrm{c}^{2}\right)$ para calcular um de seus lados e utilizar a fórmula reduzida da área: $\mathrm{A}=(\mathrm{b} . \mathrm{h}) / 2$.

Existem informações sobre dois lados e o ângulo entre esses lados? Logo, podemos usar a fórmula do Teorema das áreas: A área do triangulo é igual à metade do produto das medidas de dois lados pelo seno do ângulo entre esses lados:

$$
\text { Área }=\frac{c \cdot b \cdot \operatorname{sen} \hat{A}}{2}
$$

Dado três pontos distintos, verificar se estes não estão alinhados $(\mathrm{D} \neq 0)$;

Com os três pontos devemos calcular a distância da base: $\mathrm{d}(\mathrm{AB})$ e calcular a distância entre $o$ vértice $\mathrm{A}$ e a reta suporte ao lado $\mathrm{BC}$, utilizando uma matriz 3 × 3 ou então utilizar a fórmula direta $A=\mathbf{1} / \mathbf{2}|D|$, onde $D$ é o determinante da matriz indicada abaixo (este valor deve ser utilizado em módulo, para encontramos a área):

$$
\mathrm{D}=\left|\begin{array}{lll}
x_{1} & y_{1} & 1 \\
x_{2} & y_{2} & 1 \\
x_{3} & y_{3} & 1
\end{array}\right| \text {, onde } \mathrm{x}_{1}, \mathrm{x}_{2} \text { e } \mathrm{x}_{3} \text { são os pontos da coluna das ordenadas e } \mathrm{y}_{1}, \mathrm{y}_{2} \mathrm{e} \mathrm{y}_{3} \text { são da }
$$

coluna da abscissa.

Dar um título apropriado à figura, conforme suas características.

Dar um título apropriado à figura, conforme suas características.

Fonte: Construção das autoras

A construção da BOA (Quadro 2) ocorreu de modo indireto, inicialmente, e direto, no final do processo. No primeiro caso, foram realizadas discussões em nove oficinas didáticas promovidas em polos municipais do Curso. Estas oficinas ocorreram de forma presencial e tiveram como objetivo instigar a percepção dos itens necessários para a discussão do conteúdo em tela. 
Os estudantes evidenciaram na oficina elementos que remetem à sua vivência estudantil, como a fórmula simplificada da área de triângulo, dada por $\mathrm{A}=(\mathrm{bxh}) / 2, \quad(88,3 \%$ dos estudantes); os tipos de triângulos $(76,5 \%)$; e a desigualdade triangular (53\%). Muitos outros conteúdos, incluídos por nós na BOA, não eram conhecidos pelos estudantes, até então.

Considerando as sugestões dos estudantes, apresentamos nossa concepção acerca das características essenciais e relevantes, de forma geral, para o conteúdo da BOA, do tipo II, na discussão de triângulos para os Ensinos Fundamental e Médio. Estes itens foram amplamente discutidos, ao final das oficinas temáticas, e não houve acréscimo à lista final (Quadro 2) por parte dos estudantes.

$\mathrm{Na}$ segunda etapa do estudo agrupamos os estudantes no ambiente Moodle, em duplas (Figura 2). Esta formação de grupos no ambiente de aprendizagem ainda não tinha sido utilizada no Curso investigado e, portanto, demandou um estudo minucioso da ferramenta, para que os discentes utilizassem a modalidade de trabalho em duplas, de modo virtual, na realização das tarefas.

Os grupos e subgrupos (Figuras 2 e 3) podem ser construídos no ambiente de aprendizagem Moodle nas versões mais recentes deste software, utilizando a ferramenta agrupamento.

Figura 2 - Agrupamento de 15 grupos por polos
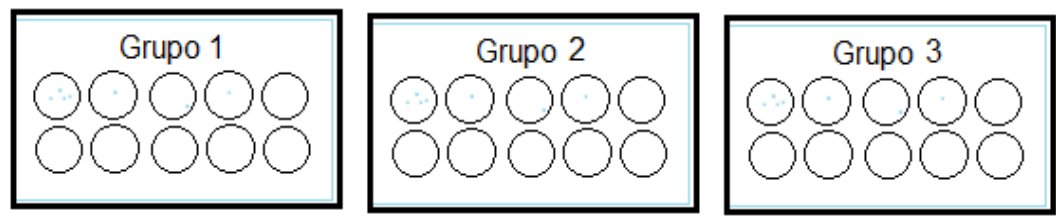

Fonte: Construção das autoras

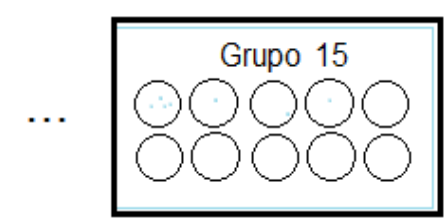

Grupo 15

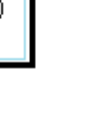

Figura 3 - Agrupamento de 48 subgrupos

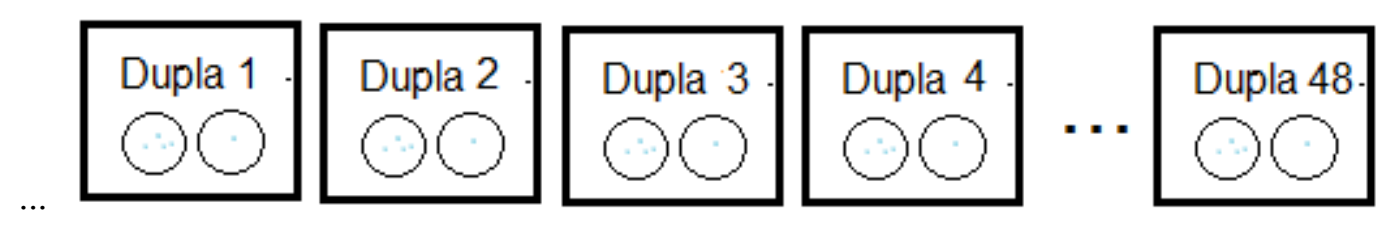

Fonte: Construção das autoras 
A organização da turma em grupos também foi utilizada na realização das etapas de controle, o que foi sugerido por Talizina (2000), quando esta estabeleceu o controle entre pares. Os estudantes, ao receberem uma tarefa, devem se organizar de modo que enquanto um trabalha na execução da tarefa de forma usual (executor) o outro executa o controle da tarefa do primeiro aluno (avaliador), atentando para o modo de sua execução. Depois foi fornecida outra tarefa de igual complexidade e trocadas as funções dos estudantes.

Agrupamos inicialmente 97 estudantes (número total de alunos matriculados), privilegiando seus polos de origem, em 15 grupos de polos com 48 subgrupos, com dois estudantes cada. A partir de então, todas as tarefas foram configuradas para serem realizadas pelas duplas.

Da etapa material ou materializada participaram 61 estudantes, tendo 39 deles obtido êxito nas tarefas realizadas. Na etapa da linguagem externa participaram 56 estudantes, tendo 33 destes participado das tarefas propostas de forma exitosa. Na etapa da linguagem interna participaram 56 estudantes, dentre os quais, 39 apresentaram êxito na realização das tarefas.

$\mathrm{Na}$ etapa mental os estudantes deveriam realizar a tarefa proposta de forma individual, sem a ajuda externa, em silêncio. A tarefa, presente no Quadro 3 é um exemplo de situação desta etapa. Ela demandava um pouco de criatividade em sua execução, sendo nosso objetivo que o estudante apresentasse uma proposta de questão diferenciada das que foram trabalhadas durante as aulas. 


\title{
Quadro 3 - Enunciado da tarefa criativa
}

\begin{abstract}
A tarefa abaixo deverá ser realizada individualmente pelo estudante, de forma detalhada, sem ajuda da BOA, e deve envolver os conceitos de áreas e/ou perímetro de triângulos quaisquer. Desejamos nesta tarefa identificar a sua criatividade sobre a temática em questão.

A Unidade IV do nosso livro texto oferece vários tipos de jogos e atividades que podem ser realizadas em sala de aula sobre temática da Geometria. Você poderá consultar a Unidade IV, site da internet, livros e outros materiais didáticos para realizar adaptações e elaborar a sua tarefa, contanto que a sua proposta seja original. Caso percebamos cópia idêntica desta tarefa em sites ou outros materiais, sua tarefa será anulada.

Você deve apresentar um jogo ou uma tarefa didática (resolução de problema, construção, problema histórico, dentre outros), que envolva o conteúdo de área e/ou perímetro de triângulos quaisquer, possível de ser aplicado em uma sala de aula do Ensino Fundamental ou do Ensino Médio. A proposta pode ser baseada em uma atividade já existente, mas você deve fazer alterações originais que demonstrem a sua criatividade na discussão do conteúdo matemático proposto. Escolha um nome para a sua atividade criativa e responda aos itens que seguem. Você pode fotografá-la e/ou filmá-la, usar computadores, calculadoras, cortar papel, .... e enviá-las também no seu arquivo. Seja criativo! Apresente também o Nome da tarefa; Ano adequado; conteúdo explorado; Material utilizado; Procedimentos e Avaliação.
\end{abstract}

Fonte: Construção das autoras

Participaram da etapa mental 55 alunos, com os seguintes resultados: 17 (30,9\%) obtiveram índices insatisfatórios, por não desenvolverem uma proposta de acordo com o que foi pedido; 19 (34,5\%) realizaram a tarefa de forma parcialmente satisfatória, tendo 15 deles $(27,3 \%)$ envolvido o conteúdo (área e perímetros de triângulos) de modo adequado, mas sem incorporar elementos novos; e apenas 4 $(7,3 \%)$ realizaram a tarefa de forma criativa, como propunha a tarefa.

A respeito da criatividade, Resende e Valdez (2006) afirmam que uma das críticas levantadas ao modelo da Teoria proposta por Galperin (2009) é que

[O] modelo formativo-conceitual, preocupado em desenvolver um método eficaz de resolução de problemas, deixa de favorecer o desenvolvimento do pensamento criativo. Esta é a única crítica que Galperin (1989c, p. 80) reconhece como pertinente, não apenas como uma insuficiência do método formativo-conceitual, mas também em função da indefinição do conceito de criatividade e a falta de compreensão de suas características pela ciência. (RESENDE; VALDEZ, 2006, p. 1228). 
Resende e Valdez (2006) afirmam ainda que Galperin (2009) estava propondo uma sexta etapa em seu modelo formativo-conceitual em busca de reformular sua teoria, cabendo aos seus colaboradores analisarem e avaliarem essa possibilidade.

Como estamos discutindo conteúdos didáticos obrigatórios da Educação Básica com estudantes do Curso de Licenciatura em Matemática, devemos prezar para que eles o dominem adequadamente. Com base nesse foco, realizamos a etapa da Linguagem Interna, desafiando os estudantes a elaborarem uma questão possível de ser aplicada em sala de aula, envolvendo a temática em tela. Obtemos como resultado que menos da metade dos estudantes (35\%) dos estudantes realizaram esta tarefa de modo aceitável. Isto caracteriza uma baixa formação da ação criativa dos estudantes participantes.

Da etapa de controle final, constituída por uma avaliação escrita, com base na qual desejávamos identificar a retenção do conceito estudado (triângulos), participaram 34 estudantes. A avaliação ocorreu de forma presencial, nos polos, sendo os estudantes acompanhados pelos tutores de cada polo. Verificamos que 23 (68\%) estudantes obtiveram êxito nesse momento do estudo.

Após concluirmos todas as etapas, solicitamos que os estudantes descrevessem, de forma detalhada, as principais discussões realizadas na disciplina e sua concepção sobre o modo como ela foi desenvolvida, em uma questão aberta e não obrigatória. A maioria dos participantes apresentou uma descrição relativamente detalhada dos elementos estudados e foi favorável às metodologias de ensino aplicadas.

Após dois meses de intervalo, sem aviso prévio, iniciando um outro semestre letivo, propusemos uma nova situação-problema aos estudantes participantes da investigação, desta vez em outra disciplina, mudando o contexto anteriormente usado, sem nenhuma orientação prévia.

Dos 34 estudantes aptos para a última etapa, apenas 31 efetivamente participaram. Destes, 28 estudantes (90,3\%) apresentaram assimilação do conceito e da ação satisfatórias, obtendo 100\% de acertos, enquanto três estudantes $(9,7 \%)$ não tiveram êxito nas situações mais complexas, aplicadas a outras áreas de conhecimento, conforme síntese apresentada na Tabela 2. 
Tabela 2 - Síntese dos resultados dos estudantes nas etapas do estudo

\begin{tabular}{|c|c|c|c|c|c|c|c|c|}
\hline & \multicolumn{2}{|c|}{$\begin{array}{l}\text { Etapa de } \\
\text { Criação } \\
\text { Diag. } \\
\text { /Oficina }\end{array}$} & $\begin{array}{c}\text { Etapa } \\
\text { Mat. ou } \\
\text { Material }\end{array}$ & $\begin{array}{c}\text { Etapa } \\
\text { da } \\
\text { Ling. } \\
\text { Extern }\end{array}$ & $\begin{array}{c}\text { Etapa } \\
\text { da Ling. } \\
\text { Interna }\end{array}$ & $\begin{array}{l}\text { Etapa } \\
\text { Mental }\end{array}$ & $\begin{array}{c}\text { Etapa } \\
\text { de } \\
\text { Controle }\end{array}$ & Retenção \\
\hline $\begin{array}{c}\mathrm{N}^{\circ} \\
\text { alunos }\end{array}$ & 72 & 34 & 61 & 72 & 56 & 55 & 34 & 31 \\
\hline $\begin{array}{l}\text { Exxito } \\
\text { tarefa }\end{array}$ & $38,8 \%$ & $\begin{array}{c}100 \\
\%\end{array}$ & $64 \%$ & $60 \%$ & $70 \%$ & $35 \%$ & $68 \%$ & $90,3 \%$ \\
\hline
\end{tabular}

Fonte: Construção das autoras

Observando os dados da Tabela 2, verifica-se uma pequena oscilação entre as etapas da pesquisa com relação ao êxito dos estudantes nas tarefas. Além disso, o número de participantes do estudo foi decrescendo ao longo dos oito meses, fato que atribuímos ao elevado índice de evasão do Curso, em todas as disciplinas e períodos letivos - entre os períodos 2007.2 e 2015.2 ingressaram no Curso de Licenciatura em Matemática a distância, um total de 2.310 estudantes, tendo concluído o Curso 222 estudantes, no mesmo período (FARIAS, 2009; UFPB VIRTUAL).

Consideramos que o momento mais complexo de nossa investigação ocorreu durante a Etapa Mental, na qual solicitamos que os participantes propusessem uma atividade para estudantes do Ensino Fundamental, relacionada ao conteúdo triângulos. $\mathrm{O}$ momento mais positivo do estudo foi o da oficina presencial nos polos, onde tivemos uma participação ativa de todos os estudantes presentes.

Durante os oito meses de duração do estudo foram aplicadas 73 questões, distribuídas em 23 tarefas, com vários graus de complexidade: produção escrita (14); levantamento do perfil da turma (01); organização dos grupos (01); oficinas temáticas (05); tarefa de aferição de controle (01); e, por último, a verificação do controle qualitativo do conteúdo assimilado (01).

Ao final do estudo, após análise da etapa de retenção, com relação às transformações sofridas pela ação no decorrer das etapas e a internalização do conceito de triângulo, constatamos que 28 de 31 estudantes foram exitosos, o 
que comprova a potencialidade das Teorias aplicadas, mesmo quando realizada na modalidade a distância.

\section{Considerações Finais}

O estudo apresentou uma discussão que consideramos relevante no que tange: ao uso da proposta teórica da Teoria da Aproximação da Atividade no curso de Licenciatura em Matemática a distância, aplicada com adultos. Verificamos que o planejamento, elaboração, execução e avaliação do sistema didático proposto neste estudo para a discussão do conceito de triângulos favoreceram a sistematização da discussão com os participantes. Outro fato relevante foi a elaboração do esquema de orientação para o estudo de triângulos na Educação Básica; e ao uso do sistema de grupos no ambiente Moodle, etapas que consideramos dinâmicas na $\mathrm{EaD}$ e que possibilitaram maior aproximação entre os participantes.

Acreditamos que é muito importante fornecer orientação adequada durante as etapas de escolarização, com intuito de evitar dificuldades futuras, propondo uma organização curricular baseada nas características essenciais e relevantes do conteúdo didático, fator este decisivo para o êxito dos estudantes. Verificamos, após dois meses de intervalo, sem prévio aviso, quando os participantes foram novamente avaliados, que eles responderam todos os itens com propriedade, segurança e demostrando domínio conceitual. Neste momento, os problemas propostos tinham maior complexidade e foram aplicados a outras áreas de conhecimento.

O arcabouço teórico adotado possibilitou um maior autocontrole dos estudantes e contribuiu para o desenvolvimento de sua autonomia, mostrando como a prática pode facilitar o desenvolvimento de capacidades e de suas habilidades. O ensino nesta perspectiva supõe novas formas de organização, diferentes da usualmente adotada nas escolas. Esta proposta é arrojada e demanda um currículo flexível, maior tempo para elaboração, execução, avaliação e controle das tarefas, o que pode gerar ansiedade nos professores, 
mas que são aspectos perfeitamente possíveis de serem atingidos. Exige desses profissionais uma postura de enfrentamento, reflexiva, dinâmica e criativa, no processo de ensino.

Verificamos que, ao final do estudo, os estudantes desenvolveram um maior autocontrole, autonomia e organização lógico-matemático, no que se refere ao conceito e a ação do conteúdo matemático considerado. Assim, constatamos que uma boa orientação pode facilitar o desenvolvimento de capacidades e de habilidades dos estudantes na modalidade a distância.

Pelo exposto, entendemos que a Teoria da Aproximação da Atividade proposta por Talizina (2000), quando aliada à Resolução de Problemas, no ensino de Matemática, possibilitou uma orientação adequada aos estudantes nos conteúdos didáticos discutidos, potencializando o ensino e a aprendizagem de conceitos matemáticos na modalidade a distância.

\section{Referências}

ARETIO, L. G.. El material impreso em la ensiñanza a distancia: actas y Congreso. $2^{\text {a }}$ ed. Madrid: UNED, 2004, p. 337.

ARETIO, L. G. La educación a distancia: De la teoría a la práctica. $3^{\text {a }}$ ed. Barcelona: Ariel, 2006, p. 328.

BRASIL. Ministério da Educação. Parâmetros Curriculares Nacionais: Matemática, Secretaria de Ensino Fundamental. $5^{\mathrm{a}}$ a $8^{\mathrm{a}}$ séries. BRASIL: MEC/SEF, 1998.

BRASIL. Ministério da Educação. Base Nacional Comum Curricular. Secretaria de Ensino Fundamental. BRASIL: MEC/SEF, 2017. Disponível em: H http://basenacionalcomum.mec.gov.br. Acesso em: 01 de agosto de 2018.

BRASIL. Ministério da Educação. Instituto Nacional de Estudos e Pesquisas Educacionais Anísio Teixeira - INEP, 2019. Disponível em: http://inep.gov.br/pisa. Acesso em: 10 de agosto de 2019.

DANTE, L. R. Tudo é matemática: livro do professor. (5 a $8^{\mathrm{a}}$ séries). São Paulo: Ática, 2000, p. 207. 
FARIAS, S.A.D. Ensino-Aprendizagem de Triângulos: um estudo de caso no Curso de Licenciatura em Matemática a Distância. 2014. 213 f. Tese (Doutorado em Educação). Centro de Educação, Universidade Federal da Paraíba, João Pessoa, 2014.

FARIAS, S.A.D.; Uma Análise da Produção Didática da Matemática a Distância: o caso da UFPB. 2009. 257 f. Dissertação (Mestrado em Educação). Centro de Educação, Universidade Federal da Paraíba, João Pessoa, 2009.

FARIAS, S. A. F; RÊGGO, R.G. Matemática e educação a Distância: resolução de problemas no ensino de geometria com o uso do Geogebra. João Pessoa: SADF, 2016. 244 p.

FARIAS, S. A. F; AZEREDO, M. A.; RÊGO, R.G. Matemática no Ensino

Fundamental: Considerações teóricas e metodológicas. João Pessoa

- PB: SADF, 2016. 204 p.

GALPERIN, P. Ya. La dirección del Proceso de Aprendizaje. In: ROJAS, L.Q.; SOLOVIEVA, Y (Org.). Las Funciones Psicológicas em el Desarrollo del Niño. México: Trillas, 2009. $113-119$ pp.

GIL, A. C. Métodos e técnicas de pesquisa social. 6ª edição. São Paulo: Atlas, 2011.

LEONTIEV, A. N. Curso de Psicologia General. Vol. I, II, III e IV. Tradução

Paulo Bezerra. São Paulo: Civilización Brasileira, 1991

PARAIBA, Estado. Referenciais Curriculares do Ensino Fundamental do Estado da Paraíba, João Pessoa: SEE/PB, 2010. 205 p.

POLYA, G.. A arte de resolver problemas. Rio de Janeiro: Interciência, 2006, p. 203.

PONTE, J. P. Investigações em Matemática. Lisboa: APM, 2005, p. 123.

POZO, J. I. (org). A solução de problemas: Aprender resolver, resolver para aprender. Reimpressão 2008. Porto Alegre: Artmed, 1998, p. 177.

RESENDE, A.; VALDÉS, H. Galperin: Implicações educacionais da teoria de formação das ações mentais por estágios. Revista Educação e sociedade, Campinas, vol. 27, nº 97, p. 1205-1232, set/dez, 2006. https://doi.org/10.1590/s0101-73302006000400007

TALIZINA, N. F. Manual de Psicologia Pedagógica. Universidade Autônoma de San Luis Potosí. Mexico: Potosína, 2000, p. 340.

TALIZINA, N. F.; SOLOVIEVA, Y. ROJAS, L. Q. La aproximación de La 
actividad em psicologia y su relación com el enfoque histórico-cultural de L. S. Vigotsky. Revista Novedades Educativas. No 230, Febrero, 2010, p. 4-8.

UFPB VIRTUAL. Apresenta informações sobre modalidades de ensino online oferecidos pela UFPB. Disponível em: < https://www.virtual.ufpb.com.br > Acesso em: 26 fev. 2009.

VAN DE WALLE, J. A. Matemática no Ensino Fundamental: formação de professores e aplicação em sala de aula. Tradução Paulo Henrique Colonesses. $6^{\text {a }}$.ed. Porto Alegre: Artmed, 2009, p. 57- 99.

VIGOTSKY, L. S. A formação da mente: o desenvolvimento dos processos psicológicos superiores. Org.: COLE, M. et al. $7^{\mathrm{a}}$ ed. São Paulo: Martins Fontes, 2007, p. 182. 